\title{
Alkantara Festival Uma pérola entre as mais belas
} Rui Pina Coelho

Em Maio de 2014, a 13a edição do Alkantara Festival Internacional de Artes Performativas apresentava-se a Lisboa num tom dolorosamente agridoce.

É certo que se comemoravam vinte e um anos desde a primeira edição de Danças na Cidade (1993-2005), a plataforma que dera origem ao Alkantara e que ajudou a tornar a dança contemporânea parte indispensável das rotinas culturais da capital. Promoveu, ainda, de forma enérgica - aquém e além fronteiras - os novos coreógrafos portugueses, e inscreveu Lisboa na rota dos mais relevantes projectos internacionais.

Mas a verdade é que o editorial, que acompanhava esta última programação, deixava perceber, pelo seu tom disfórico, toda a inquietação dos organizadores:

\footnotetext{
Se o festival preservou o eixo central do seu programa, foi forçado a abandonar espectáculos mais dispendiosos em espaços alternativos e temporários. Esta perda de palcos para artistas emergentes, fora do circuito oficial, hipoteca as futuras edições, coloca em perigo a cultura contemporânea de artes performativas em Portugal, excepcionalmente rica, e priva o festival de uma das suas funções essenciais. No final do ano, o Alkantara conta voltar a candidatarse a um subsídio estatal. Sem um sinal claro da vontade politica de manter um festival internacional contemporâneo de artes performativas em Lisboa, não repetiremos o tour de force desta edição 2014. Celebremos este Alkantara Festival como se fosse o nosso último.
}

0 milagre repetido, que as várias equipas de direcção e produção deste festival foram conseguindo criar, arquitectando programações de irrepreensivel qualidade e pertinência, via-se (vê-se!?), de facto, ameaçado de morte.

De carácter anual enquanto Danças na Cidade, e bianual após 2002, o projecto - liderado por Mark Deputter até 2008 e por Thomas Walgrave a partir dessa data tem vindo a transfigurar, sólida e paulatinamente, as artes performativas entre nós. Com um enfoque claríssimo nas práticas cénicas contemporâneas e assente no convivio entre diferentes gramáticas teatrais, foi promovendo o diálogo, a partilha e o intercâmbio entre criadores, para além de ter trazido a Lisboa (e ao Porto, na edição de 2010) muitos dos nomes mais relevantes - e originais da nova criação contemporânea internacional. Teve também o condão de promover o contacto fraterno entre criadores portugueses e de todo o mundo, proporcionado parcerias criativas e conferindo também visibilidade além fronteiras à nova criação nacional, "excepcionalmente rica", no entender dos seus promotores.

Sem o Alkantara Festival, os espectáculos, que vemos hoje em Lisboa, não seriam os mesmos. Seriam, seguramente, de qualidade inferior: disso temos a certeza.

Num pais e num momento em que vamos lentamente embrutecendo à medida que nos habituamos à violência das despedidas - de amigos, familiares, empregos, companhias de teatro, artistas -, seria fundamental não deixar partir esta importante pérola, uma entre as mais belas com que os nossos artistas nos têm brindado, trazendo até nós os desafios da nossa contemporaneidade.

E isso para nosso bem e para o enriquecimento das artes performativas em Portugal. 
$1>0$ rei no exilio, de Francisco Camacho, Danças na Cidade 93, Central Tejo - Belém, 1993, fot. Amnésia.

$2>$ Os quatro, Silvia Real, Danças na Cidade 94, Maria Matos Teatro Municipal, 1994, fot. José Fabião.

3 > Passionate Fraud, de Amélia Bentes, Danças na Cidade 95, Maria Matos Teatro Municipal, 1995, fot. Jorge Gonçalves.

4 > D. Sebastiỡo, de Francisco Camacho, Danças na Cidade 96, CAT pelo Centro Cultural de Belém, 1996, fot. Ilse Joliet.

5 > Anomalias magnéticas, de Clara Andermatt, Dança na Cidade 96, São Luiz Teatro Municipal, 1996, fot Amnésia.

6 > Sábado 2, de Paulo Ribeiro, Danças na Cidade 95 Centro Cultural de Belém, 1995, fot. Jorge Gonçalves.

$7>0$ nariz do meu pai, de Filipa Francisco \&t Bruno Cochat, Danças na Cidade 96, Acarte, 1996, fot. Moreira P.

8 > Casio tone, de Silvia Real e Sérgio Plágio, 1997, Danças na Cidade 97, Centro Cultural de Belém, 1997, fot. Jorge Gonçalves

9 > Mas distinguidas 97, de La Ribot, Danças na Cidade 97, Teatro da Trindade, 1997, fot. Del Curto.

$10>$ Herses (une lente introduction), de Boris Charmatz, Danças na Cidade 97, Teatro da Cornucópia, 1997, fot. Tanguy.

$11>$ Thomas Hauert e participantes do projecto Alma Txina, Maputo Moçambique 2002

13 > Dançar o que énosso, 2002 (Vera Mantero e Jérôme Bel), fot. Arquivo Alkantara.

12 > SOBRETUDO, de António Tavares, Danças na Cidade 97, Teatro Cinearte, 1997, fot. Aragão.

14 > Self-Unfinished, de Xavier Le Roy, Danças na Cidade 99, Teatro A Comuna, 1999, fot. Dublin

15 > Assim vai o mundo, Silvia Real, Danças na Cidade 99, Teatro Cinearte, 1999, fot. Jorge Gonçalves.

16 > Plage Tattoo, de Zita Swoon \&t Les Ballets C. de la B., Danças na Cidade 99, Teatro da Trindade, 1999, fot. Joliet I.

17 > ExtraSensory, Bruno Listopad, Danças na Cidade 99, Teatro A Comuna, 1999, fot. Jorge Gonçalves.

18 > Some English Suites, de Steve Paxton, Danças na Cidade 99, Centro Cultural de Belém, 1999, fot. Stevens R.
19 > $\dot{A}$ Bras-le-corps, de Boris Charmatz, Danças na Cidade 99, Teatro A Comuna, fot. Pierre Fabris

$20>$ Rush, de Akram Khan, Danças Na Cidade 2002, Centro Cultural de Belém, foto arquivo

21 > The Show Must Go On, de Jérôme Bel, Danças na Cidade 02, Teatro da Trindade, 2002, fot. Herman Sorgeloos.

22 > Poussée, de Néjib Ben Khalfallah, Festival Danças na Cidade 04 / Ano 0 Alkantara Festival: Dança e Performance no Mediterrâneo, Casa d'Os Dias da Água, 2004, fot. Arquivo Alkantara.

$23>$ Akabi, de Aydin Teker, Alkantara Festival - Mundos em Palco 06, Teatro Camões, 2006, fot. Elio Montanari.

24 > Visita guiada, de Cláudia Dias, Alkantara Festival - Mundos em Palco 06, Casa d'Os Dias da Água, 2006 fot. Patricia Almeida.

25 > I'm Here, de João Fiadeiro, Alkantara Festival Mundos em Palco 06, Centro Cultural de Belém, 2006 fot. Patricia Almeida.

26 | 29 > The Dialogue Series: iii. Dinozord, de Faustin Linyekula, Alkantara Festival - Mundos em Palco 08, Centro Cultural de Belém, 2008, fot. Agache Poupeney.

$27>$ Até que deus é destruido pelo extremo exercicio do beleza, de Vera mantero \&t Guests, Alkantara Festival Mundos em Palco 08, Teatro Meridional, 2008, fot. Arquivo Alkantara.

$28>$ To Be SE(r)QUENCES, de Zoitsa Noriega e Magdalena Sloncova, Alkantara Festival - Mundos em Palco 08, Teatro da Politécnica, 2008, fot. Zoitsa Noriega.

$30>$ Foreplay, a partir de A dança de roda, de Arthur Schnitzler, enc. Mpumulelo Paul Grootboom, Alkantara Festival - Mundos em Palco 10, Teatro Nacional D. Maria II, 2010, fot. Paul Grootboom.

31 > H3, de Bruno Beltrão / Grupo de Rua de Niterói Alkantara Festival - Mundos em Palco 10, Teatro Nacional São João e São Luiz Teatro Municipal, 2010, fot. Scumeck.

$32>$ Radio Muezzin, enc. Stefan Kaegi, Rimini Protokoll, Alkantara Festival - Mundos em Palco 10

São Luiz Teatro Municipal e Teatro Carlos Alberto, 2010, fot. Cláudia Wiens.

33 > Uma obra útil, enc. Gerardo Naumann, Alkantara Festival - Mundos em Palco 10, Junta de Freguesia de Santos o Velho, 2010, fot. Lorena Fernández.
34 > (M)imosa, de C. Bengolea, F. Chaignaud, M. Freitas Et T. Harrell, Alkantara Festival - Mundos em Palco 12, Centro Cultural de Belém, 2012, fot. Paula Court.

35 > Três dedos abaixo do joelho, texto e enc. Tiago Rodrigues, Mundo Perfeito, Alkantara Festival - Mundos em Palco 12, Teatro Nacional D. Maria II, 2012 fot. Magda Bizarro.

36 > Cesena, de Anne Teresa De Keersmaeker \&t Bjorn Schmelzer, Alkantara Festival - Mundos em Palco 12, Centro Cultural de Belém, 2012, fot. Anne Van Aerschot.

37 > Big Bang, enc. Philippe Quesne, Vivarium Studio, Alkantara Festival - Mundos em Palco 12, Culturgest, 2012 fot. Martin Argyroglo Callias Bey.

$38>$ Cheval, de Antoine Defoort \&t Julien Fournet, Alkantara Festival - Mundos em Palco 12, Maria Matos Teatro Municipal 2012 fot Amicale de Production Guillaume Schmitt.

39 > En attendant, de Anne Teresa De Keersmaeker Alkantara Festival - Mundos em Palco 12, Culturgest, 2012 fot. Anne Van Aarschot

$40>$ Schwalbe Cheats, de Schwalbe, Alkantara Festival - Mundos em Palco 12, Maria Matos Teatro Municipal 2012, fot. Stephan van Hesteren.

41 > The Quiet Volume, de Ant Hampton \& Tim Etchells, Alkantara Festival - Mundos em Palco 12, Biblioteca Nacional, 2012, fot. Lorena Fernandez.

$42>$ Suite N ${ }^{\circ}$ " $A B C$ ", de Encyclopédie de la Parole, composição e direcção Joris Lacoste, Alkantara Festival Mundos em Palco 14, São Luiz Teatro Municipal, 2014 , fot. Patricia Almeida.

43 > Le capital, enc. Sylvain Creuzevault, Alkantara Festival - Mundos em Palco 14, Culturgest, 2014, fot. Frédéric Marx

44 > Germinal, de Halory Goerger \&t Antoine Defoort, Alkantara Festival - Mundos em Palco 14, Maria Matos Teatro Municipal, 2014, fot. Alain Rico.

$45>$ Electric Words, de Tim Etchells, Alkantara Festival - Mundos em Palco 14, Museu da Electricidade, 2014, fot. Andreia Moutinho.

46 > Protocolo, dir. Jorge Andrade, Mala Voadora, Alkantar Festival - Mundos em Palco 14, Teatro Nacional D. Maria II, 2014, fot. António MV.

47 > Le cargo, de Faustin Linyekula, Alkantara Festival Mundos em Palco 14, São Luiz Teatro Municipal, 2014 fot. Agathe Poupeney. 


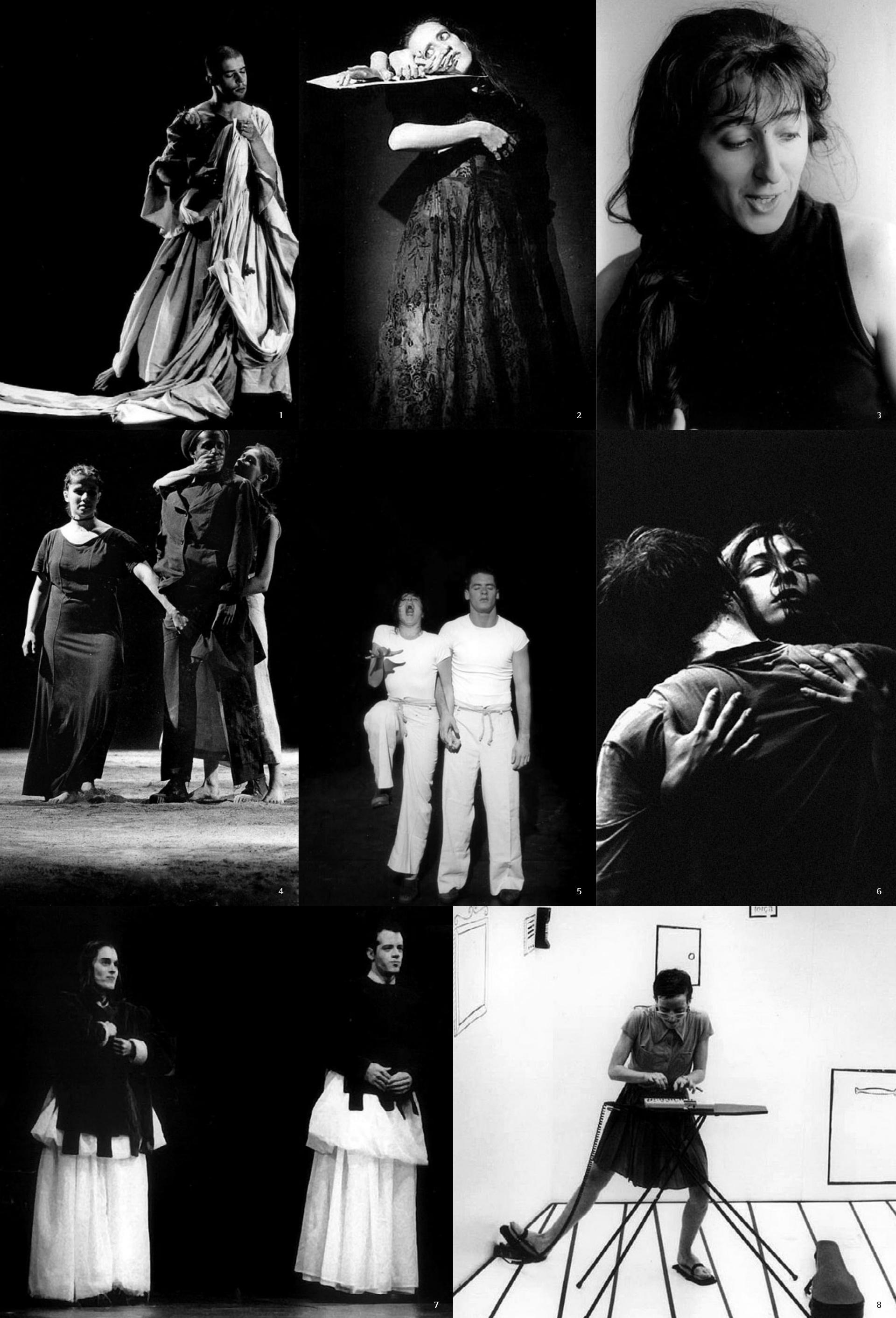




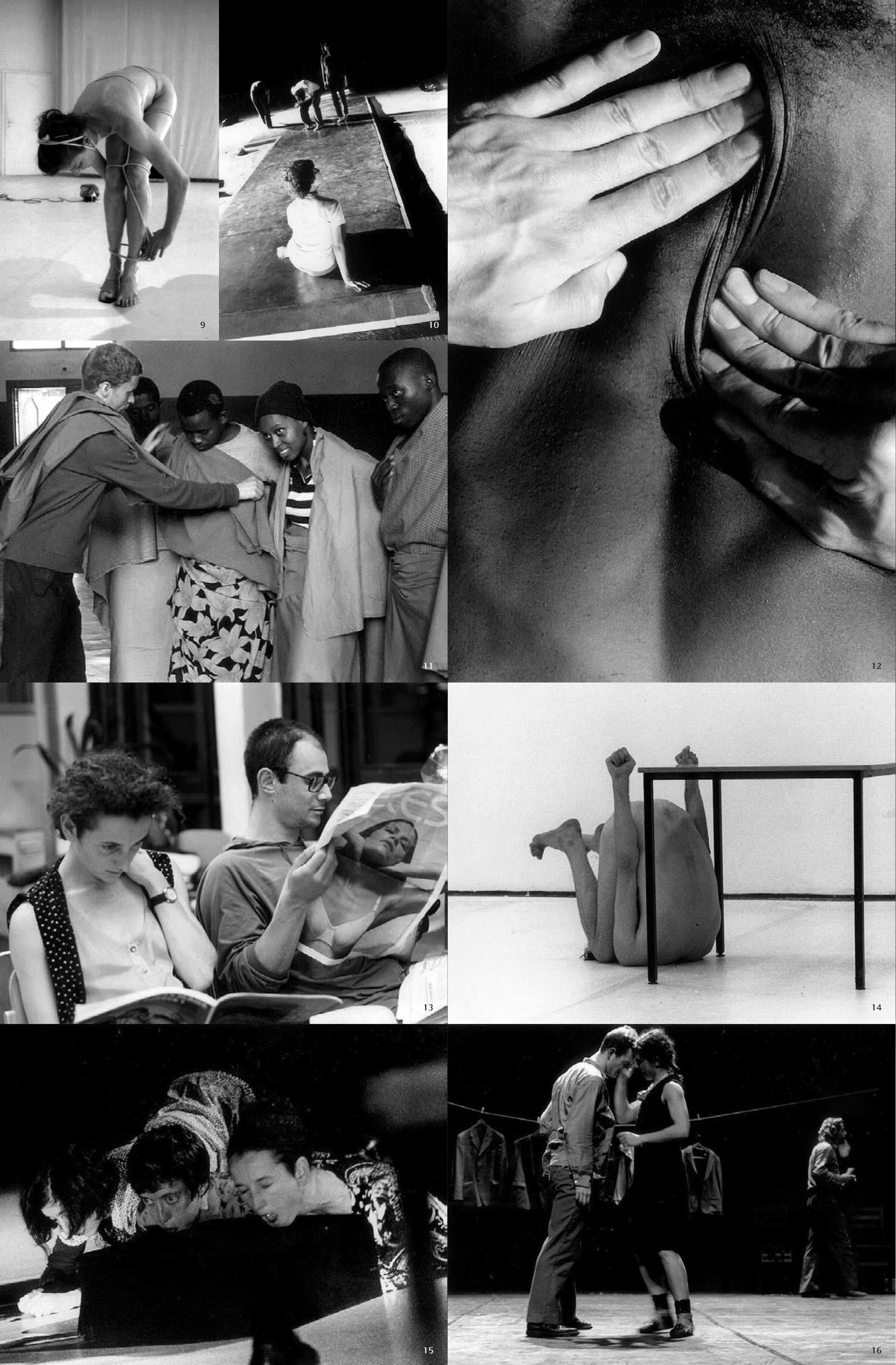




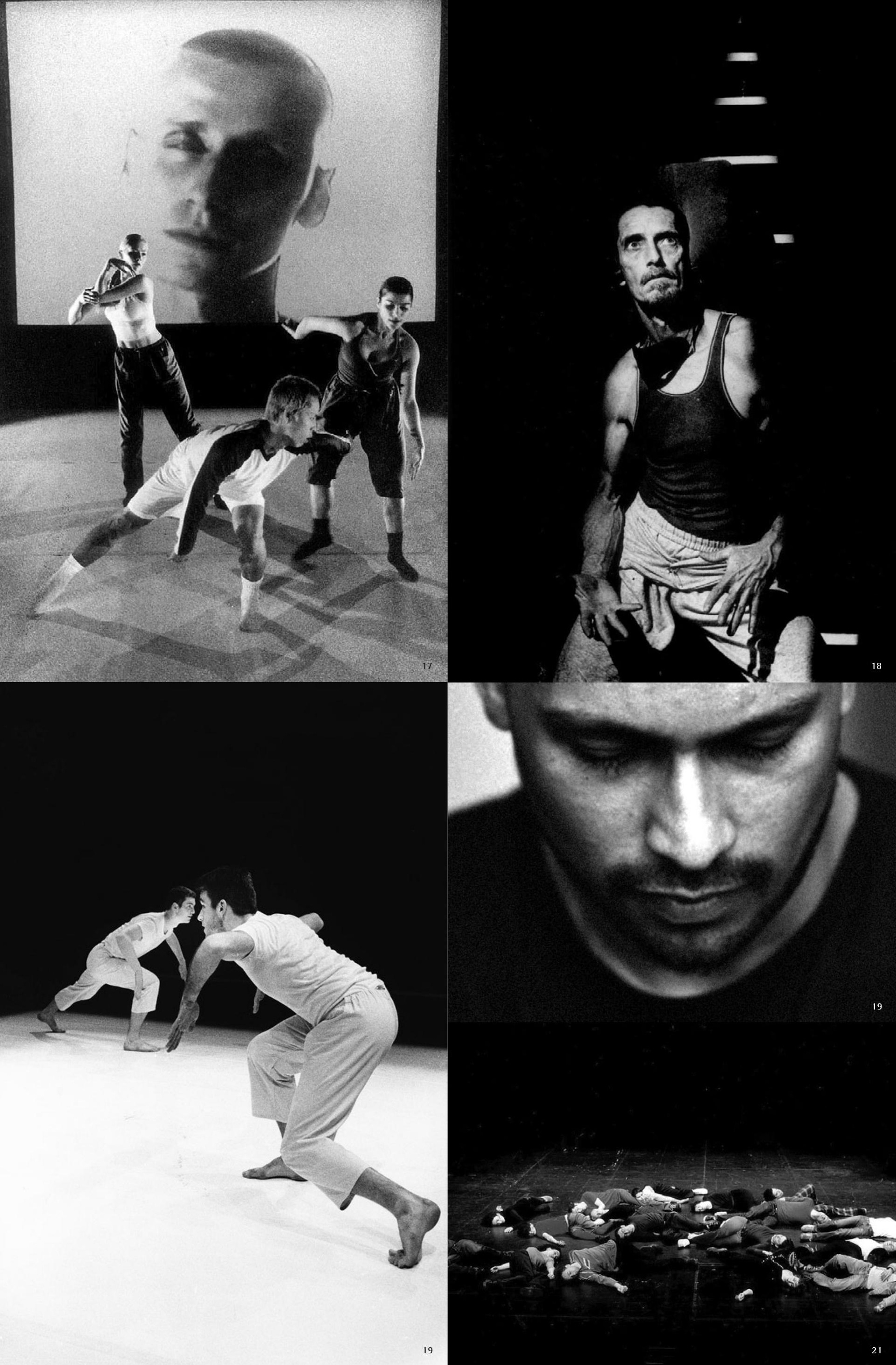



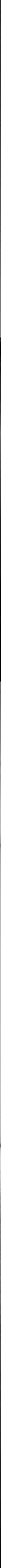


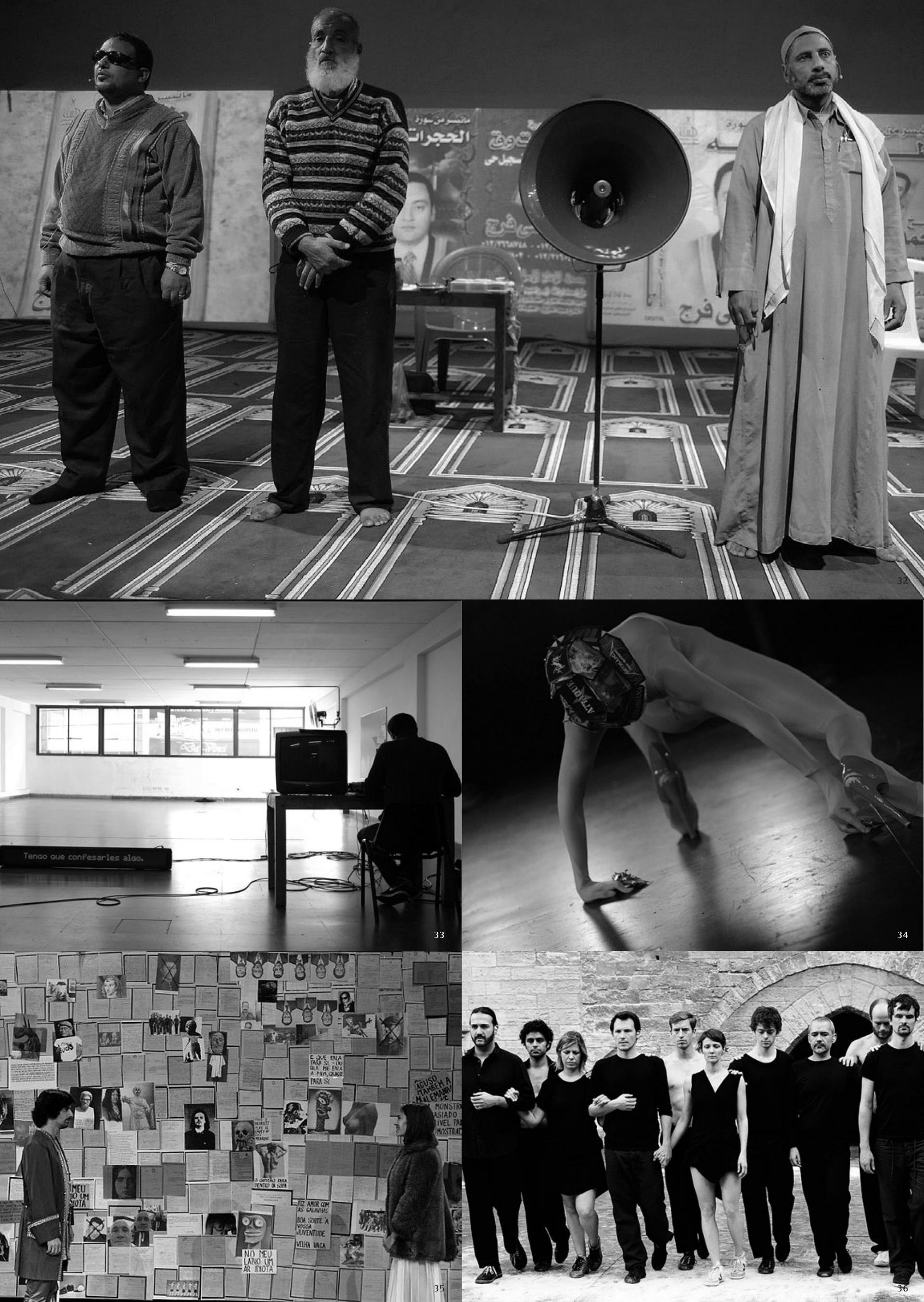




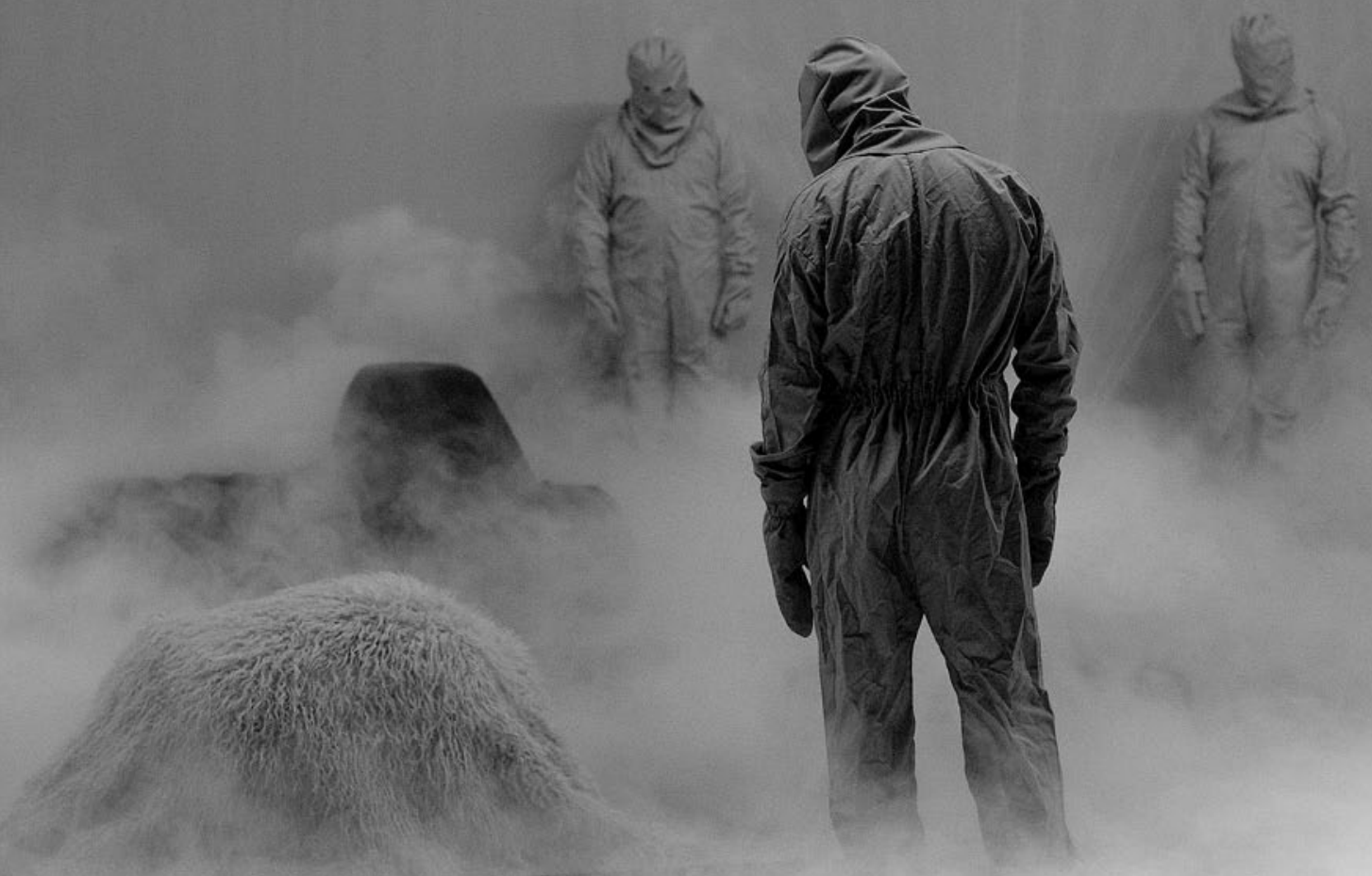

Do 11
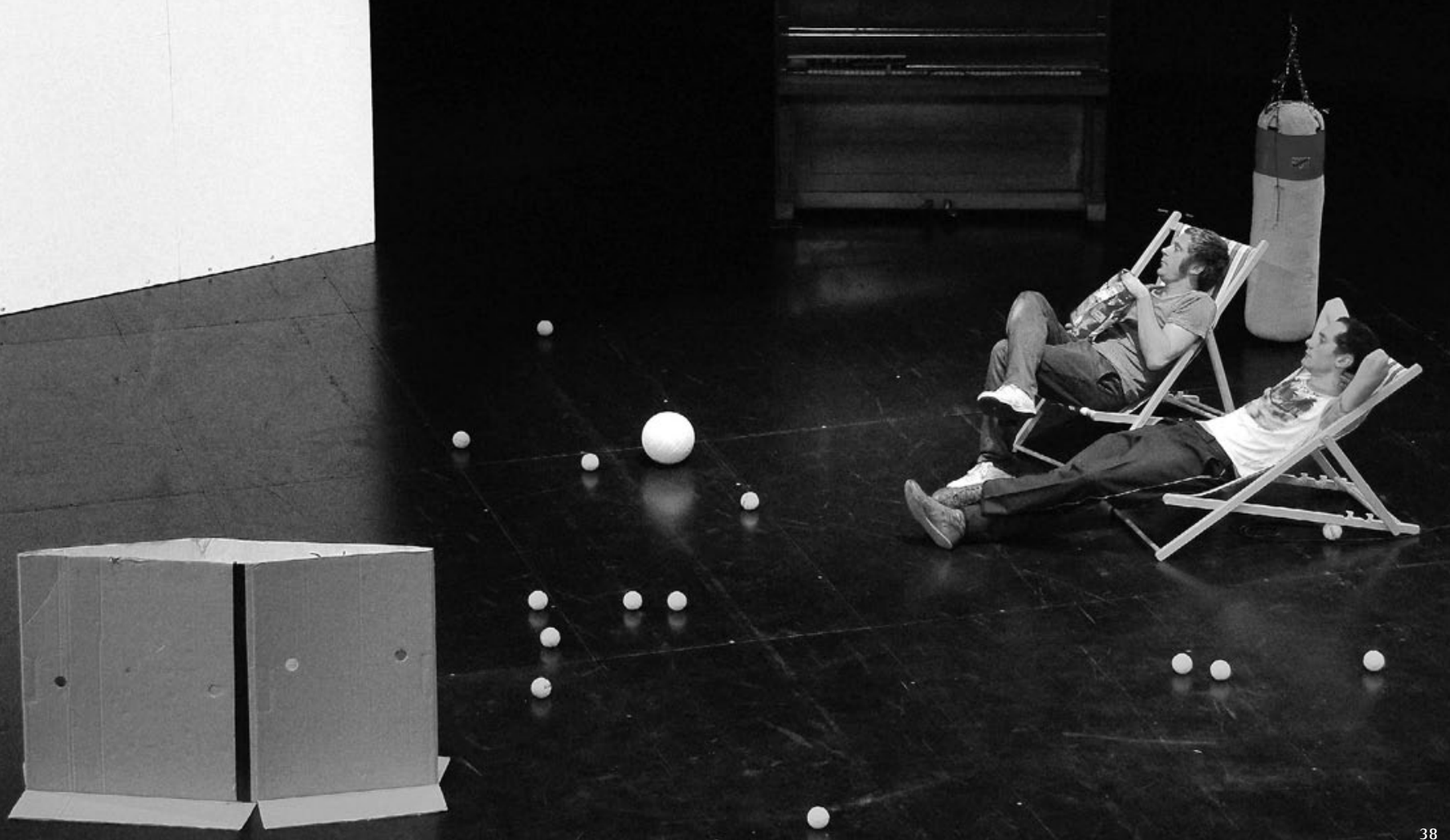

$: 9$

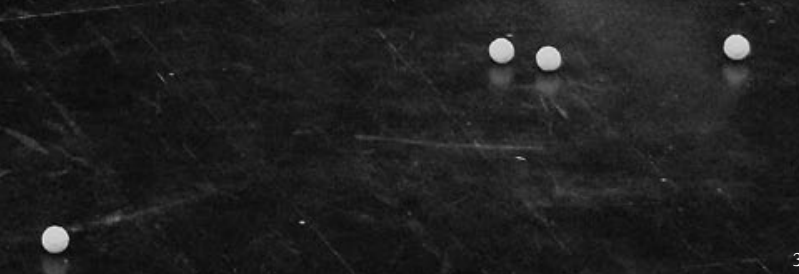




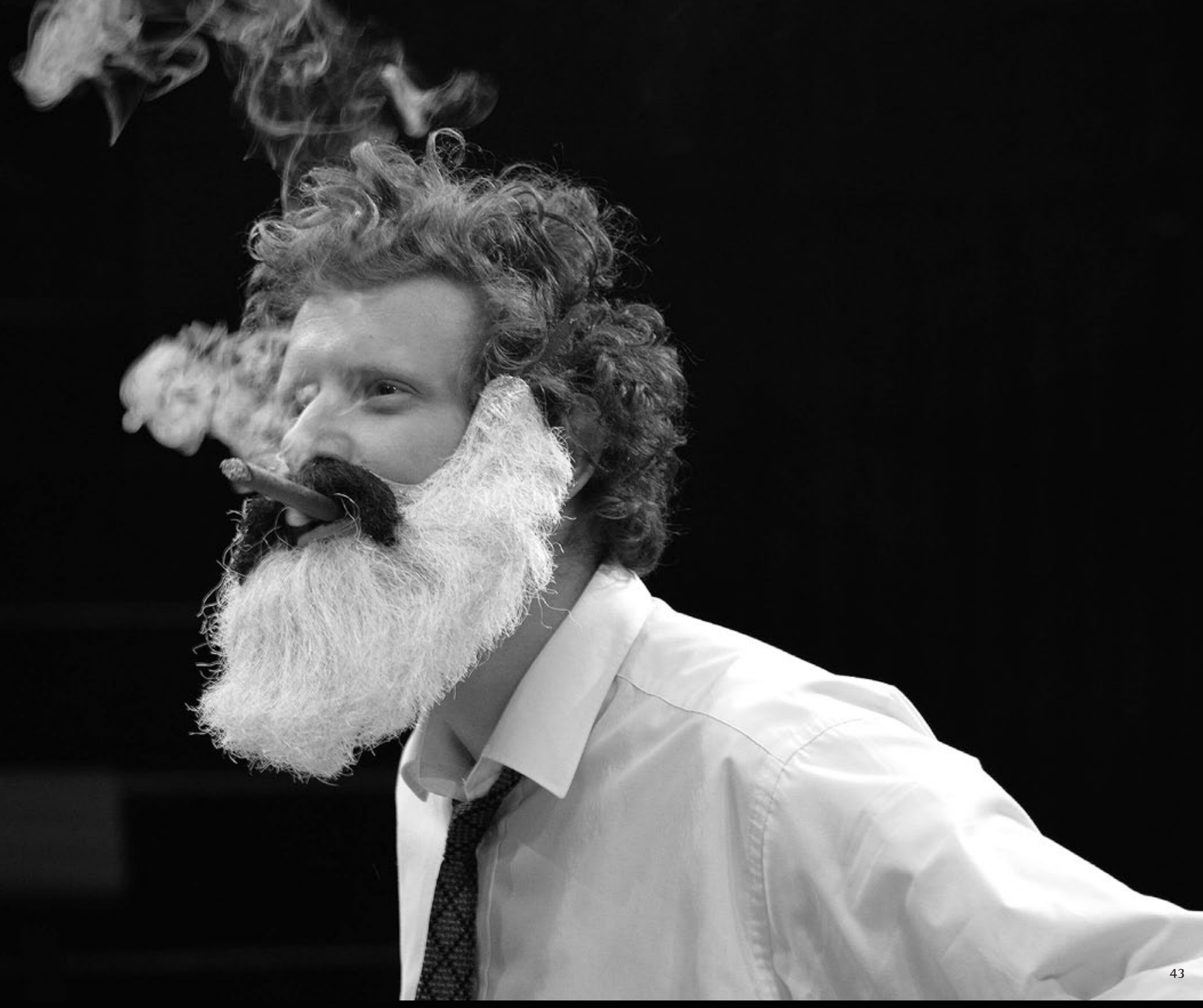

ouaiiiiiiiis

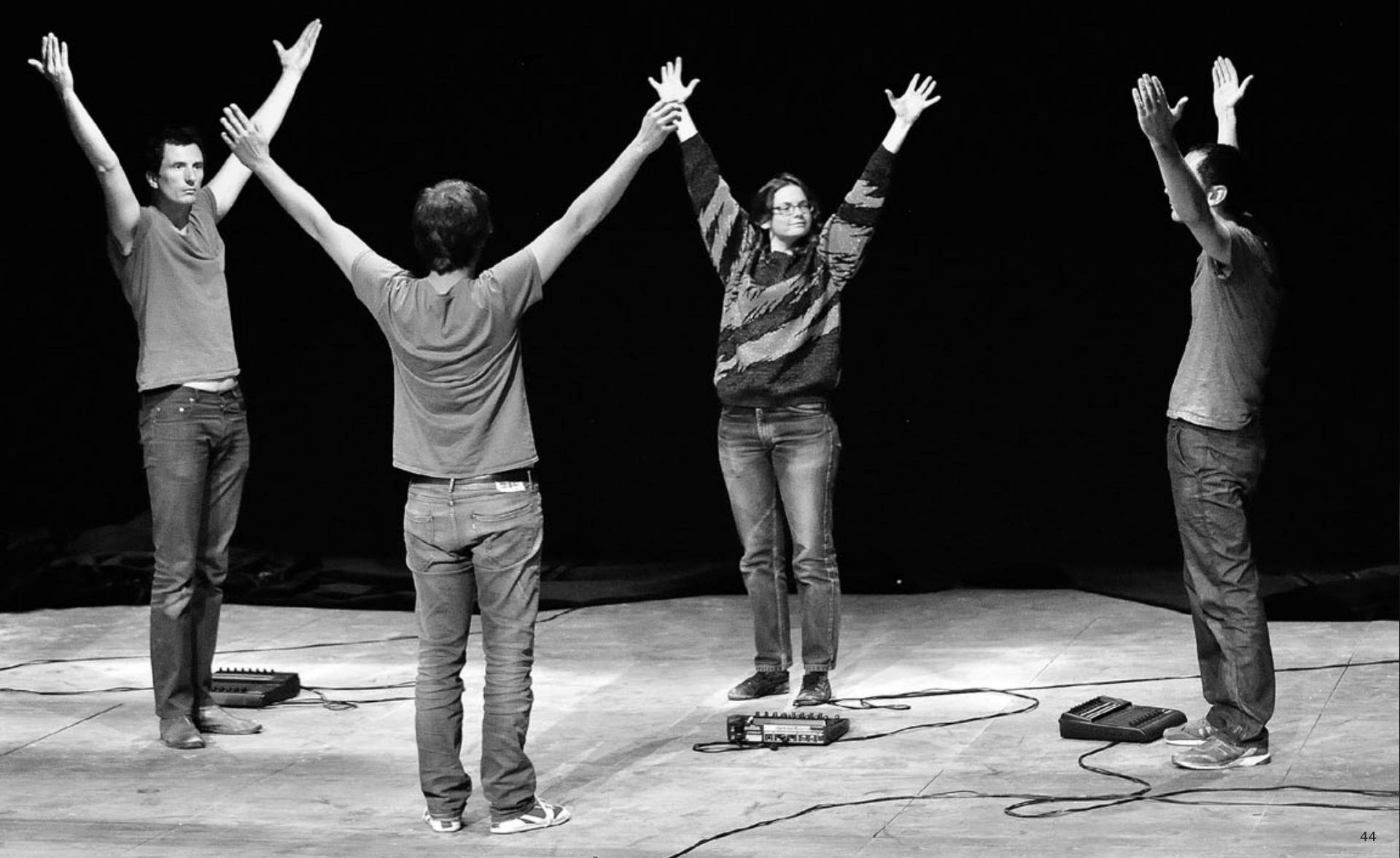




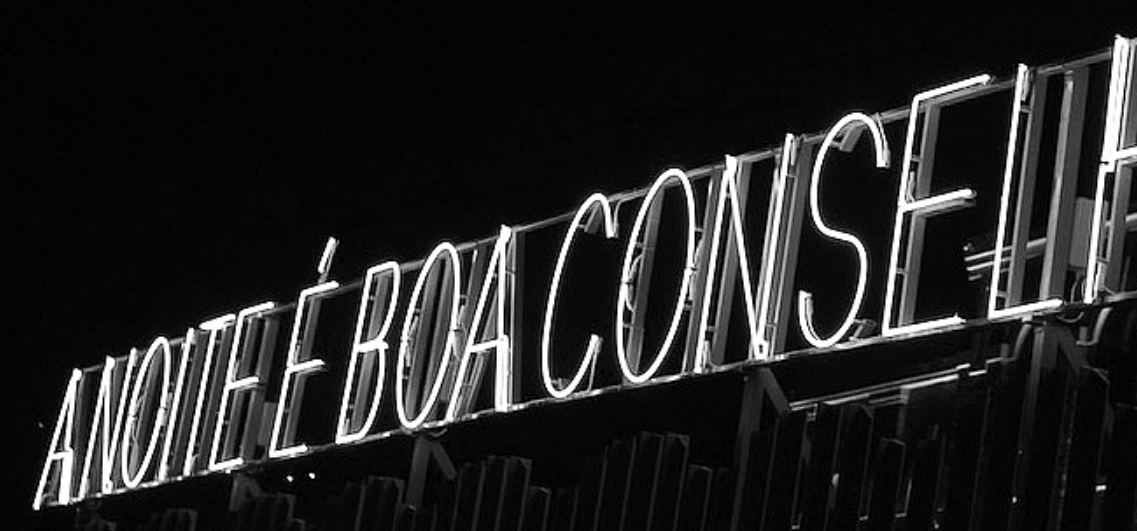

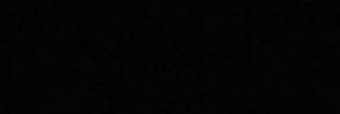




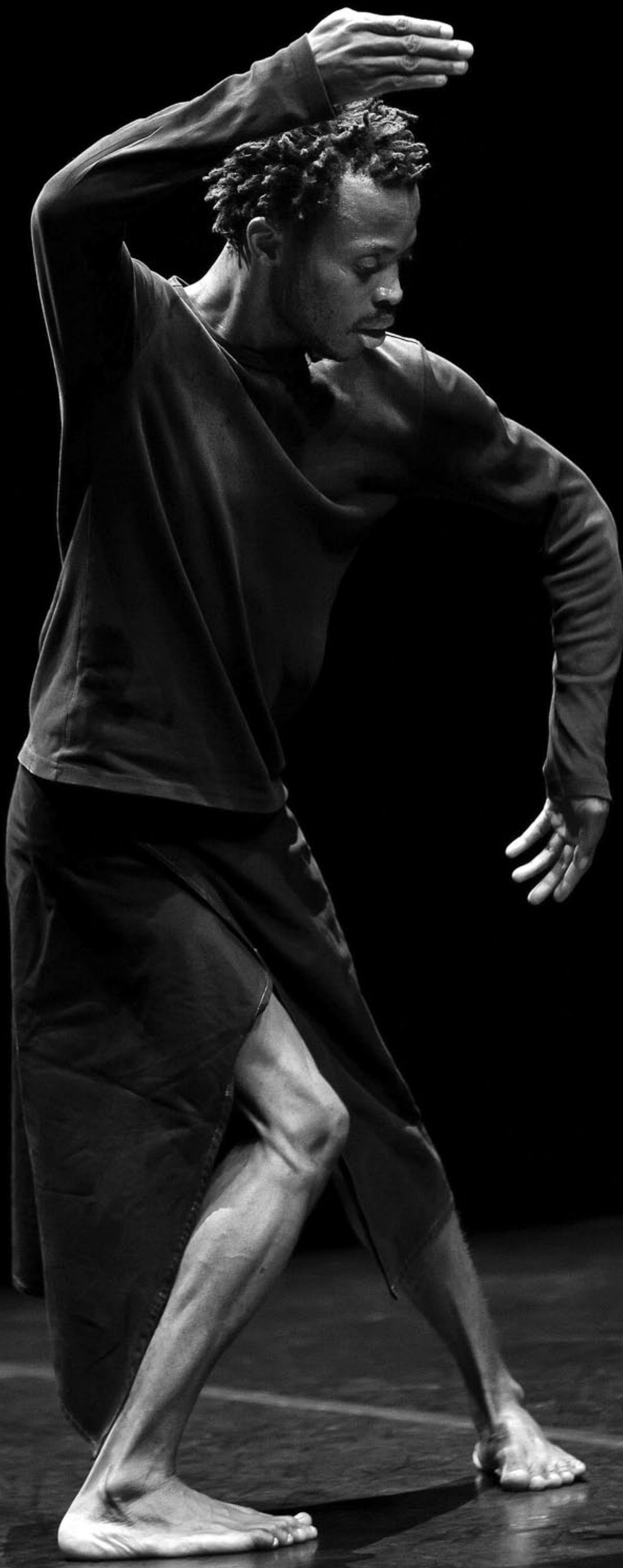

